The corresponding numbers for the other four observers of this class would be substantially the same. On the other hand, Mr. Hart requires much more red than I do in order to convert a given green into yellow-in the ratio of about $2 \cdot 6: \mathrm{I}$.

Except in the case of Mr. Hart, the colour vision of these observers is defective only in the sense that it differs from that of the majority. Their appreciation of small colour differences is as distinct as usual. In order to test this Mr. G. W. Balfour made a complete series of colour matches with revolving disks in the manner described by Maxwell and in my former paper. Six matches, of which only two are really independent, were observed, the consistency of the set being a measure of the accuracy of observation. The average error proved to be only double of that which I have found in my own observations, and rather less than that usually met with in the case of observers whose vision is normal.

In connection with what has been described above with respect to trichromic vision, it is interesting to notice that corresponding and perhaps larger differences are to be found in the vision of the so-called colour-blind. The double-refraction apparatus may conveniently be used in this investigation. With the pointer adjusted to 0 or 25 , we have in the upper half of the field pure red or pure green respectively, and in the lower half pure yellow as usual. By suitable adjustment of the gas taps two observers of this class, $\mathrm{Mr}$. T- - and $\mathrm{Mr}$. Bable to obtain perfect matches both between red and yellow, and between green and yellow, but the proportions necessary are very different for the two observers. In Mr. T_'s red and yellow match, the red is to normal vision dazzlingly bright, and the yellow almost too dark to be recognised; while the green and yellow match, however extravagant as to hue, appears reasonable in respect of brightness. On the other hand, to $\mathrm{Mr}$. B-_-'s eyes, the red of the spectrum does not look nearly so dark, and the equivalent red and yellow appear to the normal eye to be much more nearly upon a level. Although these great differences exist, there is no doubt that the vision of both observers is strictly dichromic, and that, apart from brightness, all the rays of the spectrum, from red to green, have the same effect upon their eyes.

If we wish to go beyond the fact that this vision is dichromic, and inquire whether the case is one of red blindness or of green blindness, we must be careful to consider whether the question itself has a definite meaning. If trichromic vision were always the same, and if a particular case of colour-blind vision differed from it merely by the absence of the red sensation, that vision would intelligibly be characterised as red-blind. There is reason to believe that such cases exist. In all probability the suppression of my own red sensation would lead me to make matches very nearly the same as Mr. T-_-'s; and in this sense he may fairly be called red-blind. But under the same circumstances my matches would be altogether rejected by Mr. B-_; and the question may be asked, whether his case, being certainly not one of simple red-blindness, can be brought under the head of green-blindness. To this the sufficient answer is that if I became green-blind my matches would differ from those of Mr. B- far more than if I was red-blind. The test of green-blindness would be the possibility of matches between colours which to normal eyes appear green and purple, or green and grey. Although a good deal has been said lately on this subject, I am not aware of a case in which accurate matches of this kind have been obtained from observers whose colour-vision is in other respects acute. If such cases exist, inquiry should be instituted, in order to see how far the matches would corre. spond to green-blindness of an otherwise normal eye.

We see, then, that there is dichromic vision which cannot accurately be describei as affected with red-blindness, and still less as affected with green-blindness. The difference from normal vision, being not simply one of defect, cannot be defined by any single phrase. To obtain a complete knowledge of it quantitative observations over the whole spectrum, such as those carried out by Maxwell, are necessary. It is fortunate that these observations are easier to arrange for dichromic than for trichromic vision.

That I might be able to form an opinion upon the general acuteness of his colour vision, Mr. T- was good enough to observe a series of five colour matches between red, white, blue, green, and yellow, one being left out each time. The results are given in the accompanying table; those marked "calculated" being a consistent set derived by elimination from the two marked $A$ and $B$. The good gereral agreement of the two sets of numbers is a proof that within its restricted range Mr. T-'s sense of colour is acute. The first observation in which a mixture of red and white is matched by a mixture of green and blue is the most characteristic.

\begin{tabular}{|c|c|c|c|c|c|c|}
\hline & Red. & White. & Blue. & Green. & Yellow. & Dec. 2,1880 . \\
\hline (I) \{ & $\begin{array}{l}76 \cdot 2 \\
77 \cdot 4\end{array}$ & $\begin{array}{l}23 \cdot 8 \\
22 \cdot 6\end{array}$ & $\begin{array}{l}-23 \cdot 3 \\
-21\end{array}$ & $\begin{array}{l}-76.7 \\
-79\end{array}$ & $\begin{array}{l}0 \\
0\end{array}$ & $\begin{array}{l}\text { Observed } \\
\text { Calculated }\end{array}$ \\
\hline (2) \{ & $\begin{array}{l}56 \cdot 6 \\
56 \cdot 2\end{array}$ & $\begin{array}{l}43 \cdot 4 \\
43^{\circ} 8\end{array}$ & $\begin{array}{l}-52 \cdot 3 \\
-52 \cdot 5\end{array}$ & $\begin{array}{l}0 \\
0\end{array}$ & $\begin{array}{l}-47 \cdot 7 \\
-47.5\end{array}$ & $\begin{array}{l}\text { Observed } \\
\text { Calculated }\end{array}$ \\
\hline (3) & $\begin{array}{l}68 \cdot 2 \\
69 \cdot 7\end{array}$ & $\begin{array}{l}5.5 \\
6.5\end{array}$ & $\begin{array}{l}0 \\
0\end{array}$ & $\begin{array}{l}\text { - roo } \\
\text { - } 100\end{array}$ & $\begin{array}{l}26 \cdot 3 \\
23 \cdot 8\end{array}$ & $\begin{array}{l}\text { Observed } \\
\text { Calculated }\end{array}$ \\
\hline (4) \{ & $\begin{array}{l}60 \cdot 3 \\
61 \cdot 2\end{array}$ & $\begin{array}{l}0 \\
0\end{array}$ & $\begin{array}{l}8 \\
7.8\end{array}$ & $\begin{array}{l}-100 \\
-100\end{array}$ & $\begin{array}{l}3 I^{\cdot} 7 \\
31\end{array}$ & $\begin{array}{l}\text { Observed } \\
\text { Calculated }\end{array}$ \\
\hline (5) \{ & $\begin{array}{l}\circ \\
\circ\end{array}$ & $\begin{array}{l}32 \cdot 5 \\
32 \cdot 3\end{array}$ & $\begin{array}{l}-43 \cdot 5 \\
-44 \cdot 1\end{array}$ & $\begin{array}{l}67.5 \\
67.7\end{array}$ & $\begin{array}{l}-56.5 \\
-55^{\circ} 9\end{array}$ & $\begin{array}{l}\text { Observed } \\
\text { Calculated }\end{array}$ \\
\hline A & 522 & 424 & $-5 I I$ & 35 & -470 & - \\
\hline B & $64 I$ & 405 & -470 & -199 & -377 & - \\
\hline
\end{tabular}

In conclusion I will describe an apparatus by which it is pos. sible to observe these colour-matches without rotating the disks. At the time of my first experiments, about ten years since, I was struck with the advantage which might ensue if it were possible to have the mixed colours in view during the time of actual adjustment, and I thought of a plan by which this object might be attained. The idea, which I carried out soon afterwards, was to spin an image of the disks instead of the disks themselves. An inverting prism was mounted in a tube which could be made to rotate. The axis of rotation is adjusted so as to point accurately to the centres of the disks mounted as usual. An eye applied to the prism sees the disks undisplaced as a whole, but inverted by reflection. As the tube rotates, the image of the disks rotates also, and with double angular velocity. When the speed is sufficient, the colours lying on any circle concentric with the disks are blended exactly as if the disks themselves revolved.

This apparatus is quite successful; but its real advantages of working at a smaller velocity, and of allowing adjustment while the rotation continues, are counterbalanced in practice by the inconvenience of having to look through a tube, and the uncertainty introduced by the pcssible disturbance of the match due to unequal illumination of the area occupied by the disks.

\section{MAGNETIC DISTURBANCES, AURORAS, AND EARTH CURRENTS ${ }^{1}$}

THE object of establishing a magnetic observatory is to determine at any instant the direction and magnitude of the earth's magnetic force. The direction of the magnetic force of the earth is the direction in which a small magnetic needle would point when it is freely suspended, so as to turn about an axis passing through its centre of gravity. But it is not easy to suspend a magnetic needle so as to turn freely and yet to be sure that the axis about which it turns passes accurately through the centre of gravity of the needle, and if it does not so pass, then on suspending the needle we have not only the magnetic force but also the gravitating force of the earth acting upon it to turn it about its axis, and the position which it takes up shows us the direction of these combined forces upon the magnetic needle.

This direction depends upon the mass of the needle, for to that its weight is due; it depends upon the form of the needle and the position of its centre of gravity with regard to the axis on which it is hung; it depends also on the magnetic properties of the substance, so that it is not easy to determine even the direc. tion of the magnetic force by a plan which theoretically is so very simple. Instead of attempting to make the required determinations by such a method it is necessary that a steadier mode of suspension should be adopted, and that may be done as soon as it is discovered in what vertical plane the force of gravity,

I Lecture delivered at the Royal Institution on Friday evening, June 3, 188r, by Prof. W. Grylls Adams, F.R.S. 
combined with the earth's magnetic force, will cause such a needle to rest. This is usually done by loading a steel needle at one end and then magnetising it with its poles so arranged that the extra weight of the heavier end shall balance the downward pull of the magnetic force on the other end. In this case the needle when magnetised will remain at rest in a horizontal direction, when suspended on a point on which it can turn freely in a horizontal plane.

A magnetic needle suspended in this way has been called a declination needle. Such a needle is employed in the mariner's compass, in our galvanometers for measuring currents of electricity, and in magnetic observatories for determining the declination or what is sometimes called the variation of the mannetic needle. This needle determines the position of the vertical plane in which lies the direction of the earth's magnetic force; this is called the plane of the magnetic meridian. The plane of the magnetic meridian is usually different from the vertical plane through the north and south poles, which is called the geographical meridian, and the angle between these two planes is the declination or variation of the magnetic needle.

If such a magnetic needle as I have just described be supported on horizontal knife edges instead of being supported on a point, the needle when magnetised may remain at rest balanced in a horizontal direction, one end being pulled downwards by the earth's vertical magnetic force, and the other by the force of gravity. Any change in the intensity of the vertical magnetic force of the earth will be shown by an up or down motion of the marked end of the needle. Such an instrument, called a balance magnetometer, is specially adapted for showing any changes in the vertical magnetic force of the earth, and the changes or disturbances of the earth's vertical magnetic force are determined by means of such a balance magnetometer. We have then our declination or variation needle to determine the vertical plane, called the magnetic meridian, and we have our balance magnetometer to determine any changes which may take place in the vertical magnetic force of the earth.

By the declination needle we can not only determine the plane of the magnetic needle, but by making the needle oscillate to and fro horizontally and counting the number of oscillations in a given time we can determine the horizontal pull upon the poles of the needle, i.e. the intensity of the earth's horizontal magnetic force upon the needle, just as by the swing of a simple pendulum in a vertical plane under the action of the force of gravity we can determine the pull of the force of gravity upon the bob of the pendulum. By a similar method and by a pro. perly suspended needle either the vertical force or the total magnetic force of the earth may be determined.

In order then to determine the direction of the earth's magnetic force we may make use of a declination needle to give us the vertical plane, and place the dipping needle in such a position that it will oscillate in that plane; when it comes to rest it will point in the direction of the total magnetic force, i.e. in the direction through the room of Faraday's lines of magnetic force.

In order to determine the magnitude of that force the horizontal force may be found by finding the number of oscillations of the declination needle in the way that I have already explained, and these three determinations will give us the direction and magnitude of the earth's total magnetic force.

Another method of making the required determinations is to take a coil of copper wire, which is wound on a circular frame in such a way as to be capable of spinning on a diameter of the circular frame.

Faraday showed that on turning such a coil in a magnetic field a current of electricity is induced in the coil, and the strength of this current is proportional to the number of lines of force cut by the coil. We may describe such an arrangement as a magneto-electric machine, in which the magnet employed is the earth itself.

By means of this instrument we may determine either the horizontal or the vertical magnetic force of the earth. By placing the axis vertical and spinning the coil at a given rate we may determine the horizontal force, and by placing the axis horizontal in the magnetic meridian and spinning the coil at the same rate we may determine the vertical force, the currents produced in the two cases being in the same ratio as the numbers of the lines of force cut in the two positions.

The greater the angle at which the axis of rotation is inclined to the direction of the lines of force the greater will be the number of them included in the revolving circle, and the greater the induced current produced in the coil.
Thus placing the axis in different positions we get currents of different strengths, and may readily see that we get the greatest current when the axis is at right-angles to the direction of the lines of force, i.e, to the line of the dip.

We may further make use of such a coil to find the direction of the lines of force, for if we place the axis parallel to the lines of force, the currents in opposite halves of the coil will balance one another, because each line of force is cut twice by the coil, and so no current is produced in the external circuit through the galvanometer.

If then we place the coil so as to get no current when we rotate it, then the direction of the axis of the coil is the direction of the dipping needle, i.e. of the magnetic lines of force.

We will suppose now that for some point of time, say June Ist at 12 o'clock midday, the three magnetic elements, i.e. the declination, the horizontal force, and the vertical force, have been determined, we have now to consider the changes or disturbances produced in these magnetic elements, and the connection of these changes with other phenomena, and especially the connection between auroras, earth currents, and the larger and more irregular magnetic disturbances.

I have already drawn attention to the declination needle and the balance magnetometer for measuring the changes of declination and of the vertical force.

For measurement of the changes in the horizontal force a special instrument is employed, called a bifilar magnetometer, in which a magnet is suspended by two threads, which are so placed that by their torsion acting against the magnetic force of the earth, the magnet is kept at rest in a horizontal position in a direction at right angles to the magnetic meridian.

This completes the list of instruments for our magnetic observatory.

Any change or disturbance of the horizontal force pulls this magnet round more or less in the horizontal plane, and its change of position is observed as in the other instruments. The results I have to bring before you this evening have been derived from the photographic registrations of similar instruments in different parts of the world, so that the motion of the needle bas recorded its own tale on the prepared paper which is wrapped on a cylinder driven by clockwork, and so placed as to receive the spot of light reflected by the moving needle.

First, there are regular daily and yearly changes, showing that the sun produces regular changes in the three magnetic elements which depend on the time of the day and the seasort of the year, so that the change of position and apparent motion of the sun with respect to the place of observation produce regular magnetic changes. These regular daily changes are accompanied by and have very generally been supposed to be due to electric currents or electric waves traversing the earth's crust, and a discussion by Dr. Lloyd of the observations made by Mr. Barlow in 1847 of currents on telegraph wires showed a very close relationship between the two-hourly changes of the declination needle and the changes of intensity and direction of earth currents on telegraph lines.

Both Dr. Lamont and Dr. Lloyd conclude from their com parisons of earth currents and magnetic changes that the changes of the declination needle cannot be due to the direct action of the electric current traversing the earth's crust, but that these currents or waves, extending to a considerable depth, alter by in. duction the magnetism of the earth itself, and this change of magnetism causes the observed changes in the declination needle. Thus the magnetic changes are the indirect effects of (not the earth current in its immediate neighbourhood, but of) a change in the magnetism of the earth itself, which may be due to an electric wave extending over a considerable area of the earth's surface.

The point towards which the total earth current is directed follows the sun and seems to lag two or three hours behind, but not the same distance behind at different places.

These earth currents have been ascribed to different causes : thus Dr. Lamont regards them as the results of electric force emanating from the sun; De Saussure regards them as developed by evaporation, the vapour being positively charged, and the water being negative; Dr. Lloyd regards them as effects of solar heat; whilst $M$. de la Rive ascribes them to chemical actions going on in the interior of the solid crust of the earth, the electricity being transported into the atmosphere by evaporation.

Mr. Ellis of the Greenwich Observatory has shown the intimate relation between solar action and the regular diurnal 
magnetic changes of declination and horizontal force at Greenwich Observatory during thirty-five years from I $84 \mathrm{I}$ to 1876 by a comparison of the ol servations of those elerrents. The results of his observations are shown on a large diagram which has been enlarged from his curves, and they show what a close relationship exists between solax storms and ters estial magnetic changes. There are not only daily and yearly periods of the variations of the different magnetic elements, but there also seems to be in the horizontal intensity a period of twenty-five or twenty-six days, which is the time of rotation of the sun on his axis. Other recent investigations have shown that these regular magnetic changes depend not only on the sun, but that they are also in part due to the action of the moon, and these portions depend upon the length of the lunar day and on the position of the moon with regard to the earth. Just as there are regular earth currents whose direction depends upon the sun, which we may call the solap earth currents, so there are lunar earth currents whick go through their changes under the action of the mcon, and it has been shown that the effects are produced not immediately under the moon, bat there is a lagging behind in the case of the linar earth currents, just as in the case of the solar earth currents. In the case of the lunar earth currents we cannot attribate the production of the electricity either to heat or to thermo-electric eurrents from one part to another of the earth's crust, and we must therefore look for some other source. May we not find it in the fact that the moon causes tides in the solid crust of the earth, just as she causes tides in the oceans? The earth's crust is made up of elastic materials and materials capable of yielding and altering their form to a considerable amount with the change in the direction of the full of the moon ur on them. This crust also contains magnetic substances in abundance which alter their form under the moon's attraction, and so from the changes of position of masses of magnetic matter changes are produeed in the magnetism of the eartk which must give rise to indueed currents of electricity or earth currents. Let us imagine a conductor of electricity outside the eartb, stretching from the North Pole to the equator and fixed in space, with the earth, a wagnetic body, revolving beneath it from west to east ; then it follows, from Faraday's laws of induced currents, that the revolution of the earth on its axis would cause a current in the fixed conductor in a direction from the pole to the equator.

If the conductor moved over the surface of the earth from west to east, and the earth did not revolve, or revolved at a slower rate, then the current in the conductor would be from the equator to the pole. The current depends upon the relative motion of the earth and the wire. If then we have an insulated wire running north and soutb, the tides in the earth's crust, of which I have spoken, will be equivalent to a lagging behind of magnetic matter, and so we may expect in that wire a current of electricity whose general direction would be from the equator to the pole. The position of the wire with reference to the magnetic pole of the earth would modify the direction of these earth currents, and it is quite conceivable that the position of Engl nd with regard to the magnetic pole might cause these regular earth currents to be greatest in the south-west and north-east direction. The lagging of the lumar earth currents behind the position of the moon would aiso be accounted for by the lagging of the tides tehind the moon If this is a true cause for some portion at least of the lunar earth eurrents, then the same reasoning applied to the sun may in a smaller degree apply to the case of the regular selar distonall earth currents, and may help to account for the lagging behird of the effects dne to the sun, so that the fact that the greatest solar effect happens. about $2.30 \mathrm{p} . \mathrm{m}$. may not be entirely due to the fact that that is the hottest part of the day, but may also in part depend upon the tides.

We have now to consider those more sudden changes of the suspended magnets, which are distinguished by the name magnetic disturbances. In 1874 Dr. Lloyd said of them:- "The duration and the magnitude of these oscillations are as yet outside the domain of law, and probablydepend upon so many operating causes that, like the gusts and lulls of the wind in an atmospheric storm, they will long baffle all attempts to refer them to their actuating forces, or even to reduce them to order."

Certain facts relating to these disturbances have long been known. From the series of observations started by Gauss in 1834, and made every five minutes at the same times at a variety of places, at first in Europe and afterwards in various parts of the world, the disturbing power was found to increase in northern latitudes; also it was made out that the appearance of a disturbance in several places occurred at the same time, but there were great differences in the results at different places.

In Europe the agreement was very gocd, and also in America; but the agreement between Europe ard America was not so satisfactory.

The force seemed to originate in a certain point in the interior of the earth, and the direction of the disturbing force seemed to be constant: yet sometimes there were great differences in the deviations at places not far apart, and from the result of his observations Weber was led to believe that there was a centre of disturbances which was somewhere in the neighbourhood of St. Petersburg.

However sudden and unconnected single" distrobances may seem to be, they still follow certain laws in their occurrence; Sabine fourd that they had daily and yearly variations from their mean values, and that they have an eleven-year period, which agreed with the eleven-year period of the appearance of spots upon the sun.

Disturbances are more frequent in summer than in pinter, and this applies to each hemisphere; and it has been eonfirmed by various observers that they are also subject to the infuence of the moon. Lamont says of these disturbancesy "Their cause is a force which is subject to certain laws but which do es not act constantly; the mean direction and frequency have yet to be discovered."

Observations have shown that the magnetic disturbances: and electric currents on the earth are so nearly related to one another that people naturally lcok upon the electric currents, either in the crust of the earth or in the atmosphere outside it, as the cause of the magnetic disturbances. These currents in the earth have usually been attributed to changes of temperature, because they also are found to be in some way governed by the sun.

Now let us come to more recent observations of magnetis disturbances with the improved methods of recording obervations by photography which are now available. For some years past photographic records have been taken of the magnetic elements, but the curves have teen laid aside, and very little use has been made of them; so much so that some three or four years ago a circular letter from Mr. Ellery, Director of the Melbourne Observatory, was sent round to those scientific men who were supposed to be interested in the matter to know whether it was advisable to continue the photographic records of magnetic changes at Melbourne, which is the most southern staticn, and the only station in the southern hemisphere except Mauritius, where such observations are taken. Mr. Ellery did not for one moment suppose that they were of no value, but as no use was made of them he wished to know whether the money expended might nct be better applied to another purpose. This matter has been taken up by the Kew Committee, of which Di. De La Rue is the chairman, and a recommendation was made that the directors of all observatories which possess instruments of the Kew pattern should be invited to send to Kew their photographic records, or careful tracings of them, for a given period, so that a comparison might be made of the results.

The period chosen was the month of March, 1879 , and records for the whole month have been sent from Lishon, Coimbra, Stonyhurst, Vienna, St. Petersburg, and Bombay, in the northern hemisphere, and from Melbourne and the Mauritizas in the southern hemisphere.

A preliminary account of a comparison of the decliration curves from the European stations was brought before the British Association last year at Swansea, and this evening I have to bring before you some further points which come out of these comparisons. Let us take the disturbances on March 15-16, 1879, which will illustrate some of the points which I wish to bring out prominently.

Not only do magnetic changes cccur at the same time at different stations, but there is a great similarity between them.

It must be remembered that at northern stations the horizontal force is smaller in proportion to the whole force than it is at stations nearer to the equator, so that the same disturbance will produce less effect on the horizontal force or on the declination needle in latitudes near the equator.

Also the needles at different stations are by no means in the same state of sensibility, and even at the same station they change with time, so that they are not always equally sensitive, and when they lose their magnetism they have to be re-mag netised.

We see that soon after Io a.m. G.T. on March 15, I879, there is a disturtance wave showing first a diminution and then a r 
increase in the horizontal force at St. Petersburg, Vienna, Kew, and Lisbon. At Melbourne in Australia there i; a sinilar dis. turbance at the same time both in the declination and in the horizontal furce.

Again, between 2 and 3 and between 4 and 5 p.m. there are very small disturbances showirg themselves at the same absolute time in the horizontal foree and declination curves. About 5.20 p.m. there is a well -marked increase in the horizontal force and eastward deflection of the declination ncedles. About 9.30 p.m. G.T. a storm begins which lasts for ahout an bour. It is felt in the northern and in the southern bemispheres, near to and on both sides of the equator. At all European stations the horizontal force is increased during the first part of the storm, and then diminished.

At Lisbon the vertical force is first increased and then diminished, and at St. Petersburg and Stonyhurst there is a diminution in the vertical force at the same time as at $\mathrm{Li}$ isbon. If we regard the dechination needles, we find that at St. Petersburg, Zi-ka-Wei, and Melbourne, and at Bombay, the declination westward is first increased and then diminished, whereas at Kew and Lisbon the motions are in the opposite direction.

The declination at Vienna seems to be intermediate between Kew and St. Petersburg, but the curve is incomplete.

At Bombay and the Mauritius, near $t$, but on opposite sides of the equator, the declination ncedles are deflected opposite ways. The local time at these places was from 1 to 2 o'cl rek at night.

Now in what way can we account for such maznetic disturb. ances as this? If we assume thit by magnetic induction from some cause or other the earth's magnetism is altered, then the position of the magnet which would produce the disturbance must be such that its pole which attracts the marked end of our needle must lie at the beginning of the disturbance to the east of Kew and Lisbon, to the north of Vienna, and to the north-west of St. Petersburs; the Lisbon vertical force curve also shows it to be below the surface of the earth. Hence an inductive action equivatent to a change of position of the north magnetic pole towards the geougraphical pole would account for these changes. The strengthening and weakening of a magnet with its north pole to the morth on the meridian of Vieina might possibly account for the magnetic chanyes observed between 9.30 and 10. 30 at night, Greenwich time, on March 15, 1879.

If we attempt to explain this disturbauce by currents of electricity or discharges of statical electricity in the air above the needles, then we must imagine that at first there is a strong current from the south-west over St. Petersburg, from the west over Vienna, and from the north-west over Kew and Lisbon, the vertical force needle at Lisbon showing that the current from the north-west lies somewhat to the east of $\mathrm{Li}$ ibon, that at the Mauritius this current is from the north, and at Bombay from the south.

Hence we must imagine that a current of electricity passes down from $n$ )rth-west to the south-east, going on towards the east over Vienna, and towards the north-east over St. Petersburg. This mist be kept up very much along the same line through ut the first part of the disturbance, and then the current or currents must be altered in strength in the sam: manner at all station:

We will next consider what would hirdly be called a magnetic storm, but a few very small deviations of the magnetic needle, lasting frum about 5.30 to 7.30 P.m. on March 26, 1879. Only the comparion of the originals will give the closenes of the similarity of the curve;, and the curves for Vieuna and Kew are $\mathrm{ab}$ iolutely $\mathrm{c}$-incident.

When the declination needle is deflected to the west, the horizontal force needle is deflected with its marked end towards the south, so that in this disturbance the two needles are drawn towards the suuth-west at the same time with greater or less powe; and twelve similar bend; are clearly traced out in the Vienna and $\mathrm{Kew}$ curves during the two hours. These disturbances are all so very small, that but for the comparison of photographs they would probably be lost sight of ; yet we see that the same deflections occur at the sıme instant at Kew and at Vienna, at St. Petersburg and at Melbourne. From the remarkable similarity in these disturbances and their occurrence at the same time, we should expect that the cause of distu:bance is so far remove from the places of observation that the difference of their distances from it need not be considered. This might not un reasonably be urged as an argument in support of a theory that such disturbances are due directly to the action of the sun re garded as a marnetic body. The numerical comparisons of ohservations made every five minutes on certain days preriously fixcd upon would probably never have shown the way in which these minute changes of maynetic power of the earth at widely distant places are rclated to one a nother.

In one or two cases Señor Capello and Prof. Balfour Stewart had compared the I.isbon and Kew curves for a particular dis. turlance, but the photograplic magnetic records have never before been collected from other stations, and there has been no opportunity of comparing them. Frox the precise similarity of the forms of the curves in many cases we may say that the ra'e of change of magnetic disturbances at widely distant stations is the same. There is nothin $r$ fitful or flashing in such disturbances as these of March 26. We might imagine a current in the crust of the earth or a current or transfer of electricity in the air near to, i.e. within twenty or thirty miles of each of these observatories, bat to imagine the same current and the same variations of the current at so many different station, all changing in the same way at the sa'ne instant, is difficult, unless it can be shown in what way all these changes are connected with the catase of such a regular electric discharge. It scems easier to imagine that such changes as these are due to a change produced by induction in the magnetism of the earth itself by some distant body. It is easy to show that the magnetism produced by a current in a magnetic substance round which it flows is greater in its action on a small magnetic needle than the direct action of the current itself. Hence a current flowing in the crust of the carth should produce its principal effect on a magnetic needle by the magnetic induction which the current induces in the earth itself.

Sometimes disturbances occur where at the same instant there are similar deflections of the declination needles at stations wide apart, and suddenly at one of the stations the needle no longer goes with the others, but begins to go, and continues for a considerable period to go, in the opposite direction to the others, turning when they turn, and tracing out a similar curve, but turned always in the opposite direction. Such cases occurred frequently during March, 1879, and especially on March 23, about 1.30 and about 7 p.m., Kew time, and on March 29, about 9 p.m. An examination of the principal disturbances seems to show that :

(I) A diminution in the horizontal force is accompanied by greater casterly deflections of the declination needle at St. Petersburg than at Kew.

(2) Increase of the horizontal force is accompanied by greater westerly deflections at St. Petersburg than at Kcw, or is sometimes accompanied by a westerly deflection at St. P'etersburg and an casterly deflection at $\mathrm{Kew}$.

These cases which I have taken will be sufficient to show how important it is that there should he additional magnetic obuervatories, espec:ally in the southern hemisphere, where photographic records shoull 1 be taken, so that we may learn something about the magnetism of the carth. Practically we have to rely on one excellent observatory (Melbourne) for the who'e of the southern hemisphere. Surely the time has arrived when there should be photographic registration of the magnetic elements at such an important observatory as the Cape of Good Hope, especially when the French Government has decided within the last few week's to establish a magnetic olsservatory at Cape Horn. With observatories at Melbonme, at Cape Horn, and at the Cape of Gosd Hope, the southern hemisphere would be well supplied, and pro!sably the Russian Government would then soon establish an observatory in the east of Siberia.

Now we can readily show the way in which the magnetic instruments are disturbed in a magnetic obervatory by the alteration of the strength of a magnet. Taking magnetic needles to represent the declination necdle, the inclination necdle, and the bifilar or h rizontal force ncedle, we may place an electro-magnet in a given position with regard to them, and by altering the strength of that electro-magnet may cause these needles to trace out disturbances of a very decided character. In the disturbance of March 26 the greate t motion of the ncedle was not more than about $2^{\prime}$ of angle at $\mathrm{Kew}$ or at Vienna. It would not be po:sible for me to show you the action on so small a scale.

I have as yct been speaking of only moderate disturbances, but now let us come to some of the larger ones, and I have had the opportunity, through the kindness of the Kew Committec, and the ob ervers at the various observatories mentioned, of studying the curves for the August magnetic storin which began at 10.20 a.m. Greenwich time, on August IIth, and for convenience may be divided into three storms, one lasting from 10.20 on the rrth, to I a.m. on the I2th; a sec.ond from II.30 a.m. on the 12th to 
7.20 on the $13^{\text {th }}$; and the third from II. 50 a.m on the $13^{\text {th }}$ to 7 to 8 a.m. on the I4th of August.

I have prepared a large sheet, on which these curves have been copied as accurately as possible for the first of these storms on the IIth. For this storm I have also the curves from Toronto and from Zi-ka-wei. The first storm began on August II at the same instant at all the stations. There is a decided similarity, especially in the horizontal force curves, throughout the first part of this storm, and certain points in it stand out prominently. Ai Kew, the beginning of the storm is not actually recorded, because the sheets of prepared paper on the time cylinders were changed precisely at IO.20 a.m. when the storm was beginning. The deflections are alike at Lisbon, Kew, Vienna, St. Petersburg, and after the very first sudden deflection, at Toronto also. The greatest effect is produced at St. Petersburg; the similarity between the large disturbances at Vienna and at Toronto in Canada, places differing about $6 \frac{1}{2}$ hours in time, is remarkable. About II.45, I p.m., and 2.40 p.m., there are very remarkable points of agreement.

From about 4.30 p.m. to 8 p.m. Greenwich time, i.e., from about II a.m. to 2.30 p.m. Toronto time, the deflections are opposed at Toronto, and at Vienna or Kew.

This would rather point to solar action as the cause of disturbance. In this case the Kew curve is not so much deflected as the Vienna curve, because the horizontal needle at Kew is not nearly so sensitive as at Vienna, and the relative strengths of the actual disturbing forces at the two places can only be obtained by comparison of the scale-values at the two places.

I will draw your attention to one other point on this day. At $9 \mathrm{p.m}$. the disturbances are all in the same direction, but about i p.m., whilst St. Petersburg agrees in direction with the others in a very violent phase of the storm, at Toronto the direction of the deflections is reversed, and this reversal of curves continues until about the end of the first of the three storms.

The second storm, beginning alout Ir.3O $\mathrm{a}, \mathrm{m}$. on the $\mathrm{I} 2 \mathrm{th}$, and lasting until the next morning, was the most remarkable of the three. It not only baffles the telegraph clerks, who wish to keep out earth currents from their lines, but it even goes beyond the powers of the magnetic observatories which are specially designed to watch over them. Thus, at Toronto, the line goes off the edge of the paper on which the photographic record is taken. At Melbourne the motion is so rapid, and also at Vienna, that the plate is not sensitive enough to receive the impressions; the motion is too quick even for photography. At the time of greatest disturbance, about 12.20 midday, it is very remarkable that at Lisbon, and at Zi-ka-wei, near Shanghai in China, two places nearly in the same latitude, but nearly nine hours af art in lime, the vertical force is increased in precisely the same way and to the same amount at the same instant.

At $\mathrm{Zi} \cdot \mathrm{ka}$-wei in China, the sudden change in the horizontal force on the needle amounted to about $\frac{1}{10}$ th part of the total horizontal force, and at St. Petersburg the change in the horizontal force amounted to $\frac{-1}{35}$ th part of the horizontal force, and the total force was changed by about $\frac{1}{8}$ th part of its full value.

Hence, any cause for these magnetic changes, in order to be a true and sufficient one, must be capable of producing such intense magnetic changes as these all over the surface of the earth. These magnetic changes are so large as to be quite comparable, as we see, with the earth's total force, so that any cause which is shown to be incompetent from the nature of things to produce the one can hardly be held to account for the other.

Since, as I have shown, the large disturbances and the small disturbances do not follow totally different laws, but agree equally well all over the earth, in so far as they agree we must attribute them to the same cause.

During this August storm, as also during the remarkable storm of January $3 \mathbf{I}$ last, great difficulties were experienced in working the telegraph lines, and $\mathrm{Mr}$. Preece has been lind enough to send me particulars of these storms.

I am also greatly indebted to the Astronomer-Royal for sending me traces of the earth-current photographic records taken at Greenwich Observatory during the August storm on two separate wires, one running from the north-east, and the other from the south-east, to Greenwich. The two tracings are bent opposite ways at the same time, so that when a current was running on one line towards Greenwich, on the other it was running away from it, and comparing these curves with the earthcurrent records from Derby and Haverfordwest and other places, it appears that the general direction of currents during this storm was from south-west to north-east, or from south-south-west to north-north-east, with varying intensity, the agreement being very close between the disturbances of the declination neecile al. the Blackheath and Greenwich photographic record. From Mr. Preece's record also earth-currents were violent from 10.30 a.m. on the IIth (i.e. they were noted within ten minutes of the beginning of the magnetic storm) to about $2.30 \mathrm{p} . \mathrm{m}$., and again from 9 to midnight.

They were very violent on August 12, beginning at Ir.30 a.m., the beginning of the second storm, and quieting down about 4.30 p.m., then beginning again at 7.30 and lasting until 9.30 p.m.

Again on the 13 th they are strong for $1 \frac{1}{2}$ hours, from about 5 in the morning, i.e. just about the end of the second magnetic storm.

The general direction of the earth-currents as observed at Derby or Haverfordwest, as well as at Greenwich, was from north-east to south-west.

Again on January $3 \mathrm{I}$ last another violent magnetic storm occurred, in which the currents were even more violent than in the August storm.

Intimately connected with magnetic disturbances and earth currents is the phenomenon of the aurora or polar light, which is an electric discharge in the upper regions of the atmosphere. During the August and January storms the aurora was well seen in England; it was also seen at St. Petersburg, and as far east as Siberia. It does not appear to bave been seen, although it was looked for, at $\mathrm{Zi}$-ka-wei in China by M. Dechevrens, the director of the observatory, although the magnetic storm was so violent there that the horizontal force was suddenly changed by $\frac{1}{1}$ th part of its total amount.

We may arrive at some idea of the character of the aurora by studying electric discharges in vacuum tubes, and Dr. De La Rue has already brought this subject before you in his Friday evening lecture.

We may gradually pass from electric discharges in air of ordinary density, in which we get the well-known electric spark between two surfaces, to air of less density but better conducting power, and then to air of less density still, but of such high resistance that no electricity will pass. Dr. De La Rue has shown that with $1 \mathrm{I}, 000$ cells of his battery the striking distance between two points is about six-tenths of an inch in air of ordinary density of about $760 \mathrm{~mm}$. pressure.

When the pressure in a hydrogen tube is reduced to $21.7 \mathrm{~mm}$. 8,937 cells will cause a discharge to take place through thirty inches.

When the pressure is reduced to 642 (about six-tenths of a $\mathrm{mm}$.), 430 cells will cause a discharge through the tube.

When the pressure is still further reduced to 0065 , it requires 8,937 cells to cause the discbarge, so that the spark passes more readily at a pressure of $642 \mathrm{~mm}$. than it does at a higher or a lower pressure. This is also the case with air.

The lower regions of the earth's atmosphere offer great resistance to the passage of electricity, but as we ascend the pressure diminishes and the electric resistance diminishes, until at last, at a height of between thirty and forty miles, a level is reached where the air offers least resistance to the passage of electricity, where the pressure is about 397 of a mm., and above that level the electrical resistance again increases, so that at a height of about eighty miles the battery of 11,000 cells would not cause a spark to pass.

If " e take a tube which has'not been very highly exhausted we see that the light from the positive pole extends nearly through the tube, and the dark space around the negative pole is small. As the exhaustion proceeds and the pressure of the air is diminished, the electric spark passes through greater and greater lengths and changes its character, until we get to the pressure corresponding to the least resistance. Beyond that the resistance increases, the dark space around the negative pole expands and the molecules fly about more freely; those on the negative plate being charged with electricity, and being repelled from it proceed for a long distance in straight lines, and possess the power of causing bodies on which they strike to glow. In Mr. Crookes's tubes we get very beautiful effects from this glowing of the glass tube itself, or from the glowing of substances in the path of the stream. We may regard this as a stream of molecules of gas charged with electricity, and we see the difference between this stream and the electric current in a vacuum tube at lower exhaustion by the action of the magnet upon it. In one case the current going through the molecules from pole to pole in the tube is bent out of its course by the magnet, and symmetri- 
cally by the two poles, and returns to its path, the line of least resistance, through the molecules, whereas the stream of molecules at the bigher exhaustion, carrying their electricity with them, are carried away by the electric charge upon them, and get utterly lost and scattered on striking the side of the tube, yielding up a great deal of energy in the form of heat to the tube or to the glowing platinum or other substance in the tube.

I must now show you the beautiful aurora tube which bas been seen once in this theatre, and for which I am indebted to the kindness of Dr. De La Rue. It has been brought to the right state of exhaustion to show just those effects which will help better than any description of mine to give you an idea of the character of the aurora discharge in the middle regions of the atmosphere.

By bringing a magnet to bear upon this discharge we may see the effect of terrestial magnetism on the aurora discharges in the atmosphere.

Aurora Borealis. - The aurora as seen in the north-eastern parts of Siberia, where it is often very brilliant, is described as consisting of single bright pillars rising in the north and in the north-east, gradually covering a large space of the heavens : these rush about from place to place, and reaching up to the zenith, produce an appearance as if a vast tent was spread in the heavens, glittering with gold, rubies, and sapphires.

More exact atteupts have been made to describe the aurora, and perhaps I may be allowed to quote Dalton's description of an aurora as seen by him.

A remarkable red appearance of clouds was noticed in the southern horizon, which aftorded light enough to read by, and a remarkable effect was expected. He says, "There was a large luminous horizontal arch to the southward, and one or more concentric arches northward. All the arches seemed exactly bisected by the plane of the magnetic meridian. At ro.30 otreamers appeared in the S.E, running to and fro from $W$. to E.; they increased in number, and approached the zenith, when all of a sudden the whole hemisphere was covered with them, and exhibited such an appearance as baffles all description. The intensity of the light, the prodigious number and volatility of the beams, the grand intermisture of all the primitive colours in their utmost splendour, variegating the glowing canopy with the most laxuriant and enchanting scenery, afforded an awful, but at the same time a most pleasing and sublime spectacle. But," he adds, "the uncommon grandeur of the scene only lasted one minute. The variety of colours disappeared, and the beams lost their lateral motion, and were converted, as usual, into the flashing radiations ; but even then it surpassed all other appearances of the aurora, in that the whole hemisphere was covered with it."

In his address before the British Association in 1863, Sir William Armstrong speaks of the sympathy between forces operating in the sun and magnetic forces on the earth, and notices a remarkable phenomenon seen by independent observers on September 1, 1859.

"A sudden outburst of light, far exceeding the brightness of the sun's surface, was seen to take place, and sweep like a drifting cloud over a portion of the solar suriace. This was attended with magnetic disturbances of unusual intensity, and with exhibitions of aurora of extraordinary brilliancy. The identical instant at which the effusion of light was observed was recorded by an abrupt and strongly-marked deflection in the self-registering instruments at Kew. The magnetic storm commenced before and continued after the event."

The daily and yearly periods of the magnetic changes, the change in the horizontal force depending on the sun's rotation on his axis, the agreement of the eleven-year period of magnetic disturbances, sun-spots, and auroras, show that the sun plays a very important part in causing or governing both the regular and irregular magnetic changes.

If the sun be assumed to be a very powerful magnet, then changes in his magnetism might be expected to affect the magnetism of the earth, although the effect could not be very large, unless the sun is magnetised to an intensity much greater even, compared to his mass, than the earth is magnetised. Then as there arc tides in the sea around us and probably in the earth's crust, so there are certainly very large tides in the ocean of air above us : and may not the sun and moon, by dragging this air towards them as the earth revolves, cause that friction between air and carth, and also that evaporation, which together may account for the presence of, and keep up the supply of, positive electricity in the air and negative electricity in the earth? Again, these tides in the atmosphere will cause the mass of it to lag behind the revolving solid earth, and at a height of thirty or forty miles we have a layer of air which, for air, is a comparatively good conductor of electricity. Here then we have not a lagging of the magnet behind the conductor, but a lagging of the conductor be. hind the magnet, and hence, according to the laws of Fara. day, we may expect a current or a sradual heaping up of electricity in the air in the opposite direction to the current in the earth's crust. Thus the regular tidal waves in the atmosphere would cause the gradual transfer of positive electricity from the poles towards the equator. This transfer may be of the vature of a current of electricity or of a mass of air carrying a static charge of electricity with it, for as Prof. Rowland has shown that the motion of a static charge will produce magne. tism, so we may expect from the principles of conservation of clectricity that a change in the position of a magnet will under such circumstances produce motion of the static charge of electricity. When the air becomes charged up to discharging point, then we may get the sudden discharges such as the aurora in the air and the earth current in the earth; and since the con. ducting layer of air approaches ncarer to the earth in the colder polar regions, possibly within less than twenty miles of the carth's surface, it may be found that the discharge of the aurora may even take place from earth to air by gradual slow discharge, aided as it may be by the state of moisture of the air and by change of temperature and other causes.

\section{UNIVERSITY AND EDUCATIONAL INTELLIGENCE}

Cambridge.-W. H. Calduell, B.A., of Caius College, has been nominated to study at the Zoological Station at Naples.

Mr. F. M. Balfour, F.R.S., has been elected President of the Cambridge Philosophical Society. Prof. Newton in laying down the office referred with pleasure to the removal and the change in the management of the Society's library. Since the transfer to the new room about 500 volumes have been presented to the library by Professors Humphry and Newton, Mr. J. W. Clark, Mr. F. M. Balfour, and Mr. Horace Darwin.

Open Scholarships for Natural Science have been offered by Trinity College (date of examination, March 22 next); subjects those of the Natural Science 'Tripos; by St. John's College, subjects, Chemistry, Physic:, Physiology, with Geology, Comparative Anatomy, and Botany (the last three only if notice be given beforehand), date, March 22; by Caius Collegc, date March 28, subjects, Chemistry, and either Binlogy or Physics; by Christ's, Emmanuel, and Sidney Sussex Colleges, at a common examination; subjects, Pbysics, Chemistry, Biology, and Geology; date March 28.

University Collfge, Liverpool. - The Council of the College have appointed Dr. W. A. Herdman to the professorship of natural history, founded by Lord Derby in connection with University College. Dr. Herdman is a graduate of the University of Edinburgh. He took the degree of Bachelor of Science in 1879 in the department of Natural Science, and in the same year was intrusted by Sir Wyville Thomson with the preparation of the report on the collection of Tunicula obtained during the Challenger Expedition. The Council have also appointed Dr. J. Campbell Brown to the professorship of che. mistry in the same college. Dr. Campbell Brown has for several years held the office of borough and county analyst, and of lecturer upon chemistry at the Royal Infirmary School of Medicine.

Dr. Alfxander Bain, lately Professor of I.ogic at Aberdeen, has been elected Lord Rector of that University.

\section{SOCIETIES AND ACADEMIES \\ LONDON}

Anthropological Institute, November 8.-Prof. W. H. Flower, F.R.S., vice-president, in the chair. - The following new Members were announced :-Miss Becker, Mrs. R. Crawshay, Mrs. Lloyd, Miss Mary Sheldon, Miss Eleanor E. Smith, Miss Wolfe, Prof. Acland, F.R.S., James Backhouse, William Bowman, F.R.S., Alfred T. Brett, M.D., Rev. H. Canham, John G. Garson, M.D., Hugh T. Mall, F.G.S., Capt. Hozier, W. J. Knowles, E. I lanfair Lewes, Alfred Lingard, M. B., G. I). Longstaff, M.D., William Parkin, H. Seebohm, F.L.S., Mark Stirrup, F.G.S., H. Stopes, F.G.S., Richard Thompson, Prof. F. Perceval Wright, F.I.S. ; also Dr. Josef Majer of Cracow as a Corresponding Member.-Dr. J. G. Garson exhibited some improved forms of anthropometric instruments. -Mr. Everard 